\title{
ANALYTIC SOLUTION OF GENERALIZED SPACE TIME FRACTIONAL REACTION DIFFUSION EQUATION
}

\author{
Ritu Agarwal, Sonal Jain And R. P. AgArwal
}

\begin{abstract}
The aim of this paper is to investigate the solution of a generalized space-time fractional reaction-diffusion equation associated with the Hilfer-Prabhakar time fractional derivative and the space fractional Laplacian operator. The solution of the equation in terms of the three parameter Mittag-Leffler function, is obtained by applying the Laplace and Fourier transforms. The work by K. B. Kachhia and Prajapati (2015), R. Garra et al. (2014) and S. D. Purohit (2011) and references therein follow as particular cases of our results.
\end{abstract}

Mathematics subject classification (2010): 35R11, 35C15, 33E12, $26 \mathrm{~A} 33$.

Keywords and phrases: Linear space time reaction diffusion equation, Fourier transform, Laplace transform, Mittag-Leffler function, composite fractional derivative, fractional Laplace operator.

\section{REFERENCES}

[1] A. M. Mathai, R. K. Saxena And H. J. Haubold, The H-Function Theory and Applications, Springer, New York, 2010.

[2] A. Wiman, Uber de fundamental satz in der theorie der funktionen $E_{\alpha}(x)$, Acta Math. No., 29, (1905), 191-201.

[3] A. Yildirim AND S. A. SEZER, Analytical solution of linear and non-linear space time fractional reaction-diffusion equations, International Journal of Chemical Reactor Engineering, 8, (2010), 1-21.

[4] D. BRockmANn AND I. M. SOKOLOV, Levy fights in external force fields: from model to equations, Chem. Phys., 284, (2002), 409-421.

[5] F. Polito And Z. Tomovs Ki, Some Properties of Prabhakar-type Fractional Calculus Operators, arXiv:1508.03224v3 [math.PR] (2016).

[6] F. Polito, E. Scalas, Generalization of the Space-Fractional Poisson Process and its Connection to some Lévy Processes, Electronic Communications in Probability, 21 (20), 2016.

[7] F. MAINARDI, The fundamental solutions for the fractional diffusion-wave equation, Appl. Math. Lett., 9, (1996), 23-28.

[8] H. J. Haubold, A. M. Mathai and R. K. Saxena, Solution of reaction-diffusion equations in terms of the H-function, Bull. Astro. Soc. India., 35 (4), (2007), 681-689.

[9] I. J. Podulbny, Fractional differential equations, Academic Press, New York, 1999.

[10] I. N. Sneddon, Fourier Transform, McGraw-Hill, New York, 1951.

[11] K. B. Kachina And J. C. Prajapati, Solution of Fractional Partial Differential Equation Aries in Study of Heat Transfer through Diathermanous Materials, Journal of Interdisciplinary Mathematics, 18 (1), (2015), 125-132.

[12] L. BOYADJIEV AND R. SCHERER, Fractional extensions of the temperature field problem in oil strata, Kuwait J. Sci. Engineering, 31 (2), (2004), 15-32.

[13] L. Debnath, Integral Transforms and their Applications, CRC Press, New-York-London-Tokyo, 2004.

[14] L. Debnath, Fractional integral and fractional differential equations in fluid mechanics, Fract. Calc. Appl. Anal., 6 (2), (2003), 119-155.

[15] M. CAPUto, Elasticitá e Dissipazione, ZaniChelli, Bologna, 1969.

[16] M. D'Ovidio And F. Polito, Fractional Diffusion-Telegraph Equations and their Associated Stochastic Solutions, arXiv:1307.1696, 2013. 
[17] M. Garg AND P. ManOHAR, Analytical solution of the reaction-diffusion equation with space time fractional derivative method, Kuwait Journal of science, 40 (1), (2013), 23-34.

[18] Q. Yu, F. LiU, V. ANh ANd I. TURner, Solving linear and non-linear space time fractional reactiona-diffusion equations by the Adomian decomposition method, Int. J. Numer. Meth. Engineering, 74, (2008), 138-158.

[19] R. AgARWAL, S. JAIN, AND R. P. AgARWAL, Solution of fractional Volterra integral equation and non-homogeneous time fractional heat equation using integral transform of pathway type, Progr. Fract. Differnt. Appl., 1 (5), (2015), 145-155.

[20] R. AgARWAL, S. JAIN, AND R. P. AGARWAL, Analytic solution of generalized space time advectiondispersion equation with fractional Laplace operator, J. of Nonlinear Science and Appl., 9 (6), (2016), $3545-3554$.

[21] R. GARRAPPA, Grunwald Letnikov operators for fractional relaxation in HavriliakNegami models, Communications in Nonlinear Science and Numerical Simulation 38, (2016), 178-191.

[22] R. Garra, R. Gorenflo, F. Polito and Z. Tomovski, Hilfer Prabhakar Derivative and some Applications, Applied Mathematics and Computation, 242, (2014), 576-589.

[23] R. Hilfer (Ed.), Applications of Fractional Calculus in Physics, World Scientific, Singapore, 2000.

[24] R. K. Saxena, J. P. Chauhan, R. K. Jana And A. K. Shukla, Further results on the generalized Mittag-Leffler function operator, J. of Inequalities and Appli., DOI:10.1186/s13660-015-0589-4, (2015).

[25] R. K. Saxena, A. M. Mathai and H. J. Haubold, Fractional reaction-diffusion equations, Astro phys Space sci., 305, (2006), 289-296.

[26] R. K. Saxena, A. M. Mathai And H. J. Haubold, Solution of Fractional reaction-diffusion equations in terms of Mittag-Leffler functions, Int. J. Sci. Res., 15, (2006), 1-17.

[27] R. K. Saxena, A. M. Mathai And H. J. Haubold, Reaction-diffusion systems and nonlinear waves, Astro phys Space sci., 305, 297-303, 2006.

[28] R. K. SaXena AND S. L. Kalla, On the solution of certain fractional kinetic equations, Appl. Math. Comput., 199, (2008), 504-511.

[29] S. D. Purohit, Solution of fractional partial differential equations of Quantum Mechanics, Adv. Appl. Math. Mech., 5 (5), (2011), 639-651.

[30] S. G. Samko, A. A. Kilbas and O. I. Marichev, Fractional Integrals and derivatives-Theory and applications, Gordan and Breach Science Publishers S. A., London, 1993.

[31] T. D. Frank, Nonlinear Fokkar-Planck Equations: Fundamentals and Applications, Springer, New York, 2005.

[32] T. R. PRABHAKAR, A singular integral equation with a generalized Mittag-Leffler function in the kernel, Yokohama Math. J., 19, (1971), 7-15.

[33] V. Gafiychuk, B. Datsko AND V. Meleshro, Mathematical modeling of time fractional reaction diffusion systems, Journal of Computational and Applied Mathematics, 220 (1-2), (2008), 215-225.

[34] A. YILDIRIM AND S. A. SEZER, Analytical solution of linear and non-linear space time fractional reaction-diffusion equations, International Journal of Chemical Reactor Engineering, 8, (2010), 1-21.

[35] Q. Yu, F. Liu, V. Anh And I. Turner, Solving linear and non-linear space time fractional reaction-diffusion equations by the Adomian decomposition method, International Journal of Numerical Methods in Engineering, 74, (2000), 138-158. 